\title{
Epidemiologic Features of Vulvovaginal Candidiasis among Reproductive-Age Women in India
}

\author{
Sujit D. Rathod, ${ }^{1,2}$ Jeffrey D. Klausner, ${ }^{3}$ Karl Krupp, , 5 \\ Arthur L. Reingold, ${ }^{2}$ and Purnima Madhivanan ${ }^{5,6}$ \\ ${ }^{1}$ Centre for Global Mental Health, London School of Hygiene and Tropical Medicine, Keppel Street, London WC1 7HT, UK \\ ${ }^{2}$ Division of Epidemiology, University of California, Berkeley, CA 94720, USA \\ ${ }^{3}$ Division of Infectious Diseases and Program in Global Health, University of California, Los Angeles, CA 90035, USA \\ ${ }^{4}$ Department of Health Promotion and Disease Prevention, Florida International University, Miami, FL 33199, USA \\ ${ }^{5}$ Public Health Research Institute of India, Mysore 570020, Karnataka, India \\ ${ }^{6}$ Department of Epidemiology, Florida International University, Miami, FL 33199, USA
}

Correspondence should be addressed to Sujit D. Rathod, sujit.rathod@yahoo.com

Received 20 June 2012; Revised 30 August 2012; Accepted 14 September 2012

Academic Editor: Charlene Dezzutti

Copyright ( 2012 Sujit D. Rathod et al. This is an open access article distributed under the Creative Commons Attribution License, which permits unrestricted use, distribution, and reproduction in any medium, provided the original work is properly cited.

\begin{abstract}
Background. Vulvovaginal candidiasis is characterized by curd-like vaginal discharge and itching, and is associated with considerable health and economic costs. Materials and Methods. We examined the incidence, prevalence, and risk factors for vulvovaginal candidiasis among a cohort of 898 women in south India. Participants completed three study visits over six months, comprised of a structured interview and a pelvic examination. Results. The positive predictive values for diagnosis of vulvovaginal candidiasis using individual signs or symptoms were low $(<19 \%)$. We did not find strong evidence for associations between sociodemographic characteristics and the prevalence of vulvovaginal candidiasis. Women clinically diagnosed with bacterial vaginosis had a higher prevalence of vulvovaginal candidiasis (Prevalence 12\%, 95\% CI 8.2, 15.8) compared to women assessed to be negative for bacterial vaginosis (Prevalence 6.5\%, 95\% 5.3, 7.6); however, differences in the prevalence of vulvovaginal candidiasis were not observed by the presence or absence of laboratory-confirmed bacterial vaginosis. Conclusions. For correct diagnosis of vulvovaginal candidiasis, laboratory confirmation of infection with Candida is necessary as well as assessment of whether the discharge has been caused by bacterial vaginosis. Studies are needed of women infected with Candida yeast species to determine the risk factors for yeast's overgrowth.
\end{abstract}

\section{Introduction}

Vulvovaginal candidiasis is caused by overgrowth of Candida yeast species in the vagina and is characterized by curd-like vaginal discharge, itching, and erythema [1]. Vulvovaginal candidiasis has been associated with considerable direct and indirect economic costs [2], enhanced susceptibility to HIV infection [3], and is being investigated for a potential relationship with preterm birth [4]. Treatment of vulvovaginal candidiasis is warranted when a woman presenting with a complaint of symptoms consistent with vulvovaginal candidiasis also has laboratory confirmation of the presence of Candida from a vaginal specimen. Short-course azole-based treatment regimens are considered effective and safe [5] and are accessible and affordable in most settings.

Much of the epidemiologic literature concerning vulvovaginal candidiasis reports on studies in which women were queried on their self-reported history of vulvovaginal candidiasis [6], but without laboratory-confirmation of infection by Candida. Other studies, in which investigators only measure the presence of Candida infection of the vagina [1], are not able to identify women with symptomatic vulvovaginal candidiasis disease; this latter study design is frequently employed for studies conducted in lowincome settings. Few studies have diagnosed vulvovaginal candidiasis through laboratory confirmation of infection in 
symptomatic women, and few studies have measured the incidence of confirmed cases of vulvovaginal candidiasis.

The lack of representative data on the epidemiologic features of laboratory-confirmed vulvovaginal candidiasis has been evident throughout the time in which vulvovaginal candidiasis has evolved from being considered a "nuisance infection" to a clinically relevant condition $[7,8]$. In India, only two studies have been conducted in which laboratoryconfirmed vulvovaginal candidiasis was diagnosed in a community-based sample. Bang et al. diagnosed vulvovaginal candidiasis in 35\% of 650 adult women living in rural Maharashtra state, and Prasad et al. diagnosed vulvovaginal candidiasis in $10 \%$ of 451 married, 16-22 year old women in rural Tamil Nadu state $[9,10]$. However, neither study assessed the incidence of or identified risk factors for vulvovaginal candidiasis.

As reduction of HIV transmission and of adverse birth outcomes remain public policy priorities in India [11], and studies have shown gynecological morbidity is extremely common [12-15], additional investigation of the epidemiologic features of vulvovaginal candidiasis is warranted.

\section{Materials and Methods}

We examined the incidence, prevalence, and potential risk factors for vulvovaginal candidiasis among a cohort of women originally recruited for a study to examine the relationship of lower genital tract infections and incident Herpes simplex virus type 2 infection [16]. The recruitment and baseline descriptive features of the cohort of 898 sexually active, nonpregnant women between 16 and 30 years of age from communities around Mysore, India has been previously described [17, 18]. Briefly, between 2005 and 2006, women in the cohort completed three study visits (at baseline and at three and six months), comprised of a structured interview, a clinical examination, and collection of cervicovaginal specimens for laboratory testing. Trained interviewers collected sociodemographic and behavioral information, as well as reports of symptoms associated with gynecologic morbidity.

2.1. Clinical and Laboratory Methods. Study physicians performed a pelvic examination of each participant and recorded signs of vaginal abnormalities. During the examination, swabs of the posterior fornix of the vagina and blood specimens were collected, and vaginal $\mathrm{pH}$ measured. Consistent with the US Centers for Disease Control and Prevention (CDC) 2006 diagnostic criteria [19] established prior to the baseline visit [20], vaginal Candida infection was assessed from culture (InTray Colorex Yeast, BioMed Diagnostics, White City, OR, USA) though speciation of positive samples was not recorded. Participants with positive culture for Candida were diagnosed as having vulvovaginal candidiasis if they reported vaginal itching or discharge and had vaginal erythema or discharge observed on clinical examination. As part of the Nugent-criteria scoring for laboratory diagnosis of bacterial vaginosis [21], the average number of Lactobacillus-like cells (morphotypes) detected over several visual fields in light microscopy was enumerated, and given a score corresponding to averages of $0,<1,1-4$, $5-29$, and $\geq 30$. Laboratory investigations were completed at Holdsworth Memorial Hospital and Vikram Hospital in Mysore, India. Clinical and laboratory diagnostic criteria for the gynecological conditions examined in this cohort are detailed in Table 1. Women were treated according to CDC guidelines [19].

2.2. Statistical Methods. Our outcome measure was laboratory-confirmed diagnosis of vulvovaginal candidiasis. First, we describe prevalence and incidence of vulvovaginal candidiasis using frequencies and percentages. We calculated the visit-specific prevalence of vulvovaginal candidiasis and assessed whether this prevalence changed over the course of the study. Next, we tabulated the number of women's clinic visits with various vaginal symptoms reported or vaginal signs observed. Among observations in which these vaginal signs or symptoms were recorded, we calculated the proportion in which a diagnosis of vulvovaginal candidiasis was made. Finally, we examined the relationship between the prevalence of vulvovaginal candidiasis and sociodemographic characteristics and possible risk factors. Categorical variables are the same as used in previous analyses; cut-points of previously continuous measures were defined to create balanced strata of participants at the baseline visit $[16,17]$. We used a separate univariable regression model for each characteristic and risk factor. While counts (e.g., the number of diagnoses of vulvovaginal candidiasis) are reported as observed, percentages, prevalences, trends in prevalence, $95 \%$ confidence intervals, and $P$ values were estimated using generalized estimating equations (GEE) regression models. GEE allows for parameter estimation when observations are correlated, in this case, due to multiple observations per participant over the course of the study. The GEE models were specified with binary family, identity link, and exchangeable correlation. The GEE models were bootstrapped with 500 repetitions to estimate robust standard errors.

Statistical analysis was conducted using Stata 11.2 (Stata Corp, College Station, TX, USA). The study was approved by the Committee for the Protection of Human Subjects at the University of California, Berkeley, and the Asha Kiran Institutional Review Board of Mysore, India; all participating women provided written informed consent.

\section{Results}

The 898 women participating in the study contributed a total of 2551 study visits, with 800 women (89\%) attending all three study visits and another 53 women (6\%) attending two visits. The median age of the women at the baseline visit was 26 years (Interquartile range [IQR] 24-29 years), and participants had been with their current sex partner for a median of nine years (IQR 6-12 years). Over one-quarter of the women had no formal education (27\%). Nearly one in three women identified as Muslim (29\%). Few women were nulliparous (15\%), and very few women reported using oral contraception, condoms, or an intrauterine device at any 
TABLE 1: Diagnostic criteria and treatment given for laboratory- and clinically-diagnosed gynecological conditions, Mysore, India $2005-2006$.

\begin{tabular}{|c|c|c|c|}
\hline Diagnosis & Diagnostic criteria & Laboratory device & Treatment \\
\hline Candida infection & Positive culture & $\begin{array}{l}\text { InTray Colorex Yeast, } \\
\text { BioMed Diagnostics, } \\
\text { White City, OR, USA }\end{array}$ & None \\
\hline Vulvovaginal candidiasis & $\begin{array}{l}\text { Positive culture for Candida infection } \\
\text { and one clinical sign (vaginal } \\
\text { erythema or discharge) and one } \\
\text { reported symptom (vaginal pruritis or } \\
\text { discharge) }\end{array}$ & & $\begin{array}{l}150 \text { mg oral } \\
\text { fluconazole, single } \\
\text { dose }\end{array}$ \\
\hline Trichomonas vaginalis & $\begin{array}{l}\text { Positive culture or positive saline wet } \\
\text { mount microscopy }\end{array}$ & $\begin{array}{l}\text { InPouch, BioMed } \\
\text { Diagnostics, White } \\
\text { City, OR, USA }\end{array}$ & $\begin{array}{l}2 \mathrm{~g} \text { oral } \\
\text { metronidazole, } \\
\text { single dose }\end{array}$ \\
\hline $\begin{array}{l}\text { Bacterial vaginosis, } \\
\text { laboratory }\end{array}$ & $\begin{array}{l}\text { Score of } 7-10 \text { on Nugent criteria from } \\
\text { Gram stain }\end{array}$ & & None \\
\hline $\begin{array}{l}\text { Intermediate flora, } \\
\text { laboratory }\end{array}$ & $\begin{array}{l}\text { Score of } 4-6 \text { on Nugent criteria from } \\
\text { Gram stain }\end{array}$ & & None \\
\hline $\begin{array}{l}\text { Abnormal flora, } \\
\text { laboratory }\end{array}$ & $\begin{array}{l}\text { Score of } 4-10 \text { on Nugent criteria from } \\
\text { Gram stain }[21]\end{array}$ & & None \\
\hline $\begin{array}{l}\text { Bacterial vaginosis, } \\
\text { clinical }\end{array}$ & $\begin{array}{l}\text { Positive on at least three of four Amsel } \\
\text { criteria (elevated pH, positive whiff } \\
\text { test, clue cells observed, discharge } \\
\text { observed) [22] }\end{array}$ & & $\begin{array}{l}400 \text { mg oral } \\
\text { metronidazole, bid } \\
\text { for } 7 \text { days }\end{array}$ \\
\hline $\begin{array}{l}\text { Herpes simplex virus } \\
\text { type } 2\end{array}$ & $\begin{array}{l}\text { Index value }>1.1 \text { on ELISA test of } \\
\text { serum }\end{array}$ & $\begin{array}{l}\text { Focus Technologies, } \\
\text { Cypress, CA, USA }\end{array}$ & $\begin{array}{l}\text { Acyclovir } 400 \mathrm{mg} \\
\text { tid for } 7-10 \text { days }\end{array}$ \\
\hline
\end{tabular}

point during the study. Furthermore, less than 5\% reported having oral sex or having had more than one lifetime sex partner. No woman reported douching or smoking tobacco. Throughout the duration of the study, the mean prevalences of reproductive tract infections were as follows: Trichomonas vaginalis (6\%), clinical diagnosis (Amsel criteria) of bacterial vaginosis $(12 \%)$, laboratory diagnosis (Nugent criteria) of bacterial vaginosis (16\%), and infection with Herpes simplex virus-type $2(13 \%)$. At least 30 Lactobacillus morphotypes were detected on the majority (66\%) of Gram stains of vaginal swabs, with smaller proportions of swabs with 5-29, $1-4,<1$, and 0 morphotypes detected $(11,5,6$, and $12 \%$, resp.).

3.1. Vaginal Signs and Symptoms and Diagnosis of Vulvovaginal Candidiasis. Including all three study visits for which laboratory confirmation for diagnosis of vulvovaginal candidiasis was available ( $n=2528 / 2551,99 \%)$, we found that substantial proportions of the women reported vaginal itching $(29 \%)$ or vaginal discharge $(31 \%)$ or had vaginal erythema $(9 \%)$ or vaginal discharge $(35 \%)$ on examination. The positive predictive values of these signs and symptoms for predicting vulvovaginal candidiasis were low. A minority of women with these symptoms or signs was subsequently diagnosed with vulvovaginal candidiasis $(18,15,25$, and $18 \%$, resp.). Combinations of the vaginal signs and symptoms were increasingly rare, though the probability of a correct diagnosis of vulvovaginal candidiasis increased to $41 \%$ when both signs and both symptoms were present (Table 2).
3.2. Diagnosis, Prevalence, and Incidence of Vulvovaginal Candidiasis. Candida was detected in $885 / 2528$ (35\%) vaginal specimens tested on culture. Of the 885,180 (20\%) satisfied the case definition for diagnosis of vulvovaginal candidiasis, while the remaining $705(80 \%)$ were considered asymptomatic infection.

The prevalence of vulvovaginal candidiasis declined over the three study visits from $77 / 893$ (9\%) at baseline to $65 / 840$ at three months $(8 \%)$ and $38 / 795(5 \%)$ at six months $(P$ value for trend $<0.001)$. The incidence of vulvovaginal candidiasis was modest: Of the 1487 baseline or three month study visits in which a woman was not diagnosed with vulvovaginal candidiasis, 72 (5\%) were positive for vulvovaginal candidiasis at the next study visit. Repeat diagnoses of vulvovaginal candidiasis were common. Of the 137 baseline or three-month study visits in which a woman was diagnosed with vulvovaginal candidiasis, 30 (28\%) were again diagnosed with vulvovaginal candidiasis at the next study visit.

3.3. Cross-Sectional Analysis of Vulvovaginal Candidiasis. We did not find strong evidence for associations between sociodemographic characteristics and the diagnosis of vulvovaginal candidiasis. The prevalence of vulvovaginal candidiasis among women who first had sex before 15 years of age (Prevalence 4.4\%, 95\% CI 2.6, 6.3) appeared lower than for women who first had sex between 15 and 18 years (Prevalence $7.5 \%, 95 \%$ CI $6.1,9.0$ ) or over 19 years of age (Prevalence $8.2 \%, 95 \%$ CI 5.5, 11.0). There was a large difference in the prevalence of vulvovaginal candidiasis 
TABle 2: Prevalence of observed clinical signs, reported symptoms, and diagnosis (positive predictive value) of vulvovaginal candidiasis, Mysore, India 2005-2006.

\begin{tabular}{|c|c|c|c|c|}
\hline $\begin{array}{l}\text { Vaginal sign observed } \\
\text { or symptom reported }\end{array}$ & $\begin{array}{c}\text { Prevalence } \\
(n=2528 \\
\text { clinical visits })\end{array}$ & $\begin{array}{l}\% \text { prevalence } \\
(95 \% \mathrm{CI})^{* *}\end{array}$ & $\begin{array}{l}\text { Diagnosed with } \\
\text { vulvovaginal } \\
\text { candidiasis }\end{array}$ & $\begin{array}{l}\text { \% diagnosed with } \\
\text { vulvovaginal candidiasis } \\
(95 \% \mathrm{CI})^{* *}\end{array}$ \\
\hline Pruritis reported & 735 & $29.0(26.8,31.2)$ & 132 & $17.8(14.8,20.8)$ \\
\hline Discharge reported & 782 & $31.0(29.0,32.9)$ & 122 & $15.3(12.5,18.1)$ \\
\hline Erythema observed & 239 & $9.5(8.2,10.8)$ & 61 & $24.8(18.7,30.8)$ \\
\hline Discharge observed & 894 & $35.4(33.4,37.5)$ & 162 & $17.6(14.9,20.3)$ \\
\hline None & 887 & $35.1(33.0,37.2)$ & - & - \\
\hline Any one & 916 & $36.2(34.3,38.1)$ & - & - \\
\hline Any two & 492 & $19.5(17.8,21.1)$ & 84 & $16.7(13.3,20.1)$ \\
\hline Any three & 182 & $7.2(6.1,8.3)$ & 75 & $40.1(33.7,47.9)$ \\
\hline All four & 51 & $2.0(1.4,2.6)$ & 21 & $40.9(27.6,54.2)$ \\
\hline
\end{tabular}

** Percentages and 95\% confidence intervals calculated using generalized estimating equations, with binary family, identity link, and exchangeable correlation.

among those women with bacterial vaginosis diagnosed by clinical (Amsel) criteria (Prevalence 12.0\%, 95\% CI 8.2, $15.8)$, compared to those women who were not diagnosed with bacterial vaginosis by clinical criteria (Prevalence 6.5\%, 95\% CI 5.3, 7.6). We did not find evidence of differences in the prevalence of vulvovaginal candidiasis by other laboratory diagnoses or behavioral characteristics (Table 3).

\section{Discussion}

We examined the incidence, prevalence, and potential risk factors for vulvovaginal candidiasis among a cohort of reproductive-age women in Mysore, India. Among this cohort, we found evidence that a presumptive diagnosis of vulvovaginal candidiasis based only on presence of signs or symptoms, in absence of laboratory confirmation, would be mostly incorrect. Consistent with previous research [24], we could not identify behavioral risk factors for vulvovaginal candidiasis, which provides impetus for additional investigation into intrinsic factors such as the composition of vaginal flora, the presence or absence of genetic factors, and the features of the host and local immune response.

Vaginal discharge, itching, and erythema, while quite common, were insufficient to diagnose vulvovaginal candidiasis in the absence of laboratory confirmation. Had syndromic diagnosis been used to diagnose vulvovaginal candidiasis in this cohort, the positive predictive values would have been very low $(15-41 \%)$. Our results are consistent with other studies detailing the overtreatment that results from the use of syndromic diagnosis based on vaginal discharge to diagnose vaginal conditions [25-28]. Previous findings also demonstrate that a minority of women with vaginal discharge have vulvovaginal candidiasis [25, 2931]. Thus, the diagnosis of vulvovaginal candidiasis based solely on signs or symptoms leads to overestimation of the prevalence of vulvovaginal candidiasis and its overtreatment, while leaving the actual cause of the vaginal symptoms untreated. This finding of misdiagnosis based on symptoms is also relevant for women who self-diagnose vulvovaginal candidiasis.
The prevalence of laboratory-confirmed vulvovaginal candidiasis we observed is consistent with the results of two other community-based studies in India $[9,10]$. Given that reproductive tract conditions account for nearly half of the days of illness experienced among women in this region of India [32], it is critical to understand the incidence and prevalence of individual conditions; to our knowledge, this is the first study from India to describe the incidence of and possible risk factors for vulvovaginal candidiasis.

The study visit-specific point prevalence of vulvovaginal candidiasis in this cohort decreased from $9 \%$ to $5 \%$, and $72 \%$ of treated women were negative for vulvovaginal candidiasis at their next study visit, indicating successful provision of treatment. Only $20 \%$ of those infected with Candida were diagnosed as having vulvovaginal candidiasis, much lower than the $53 \%$ found in a community-based study in Tamil Nadu, India [9]. We were not able to determine whether the $28 \%$ of women with a diagnosis of vulvovaginal candidiasis on two consecutive visits were cases in which, despite treatment, vulvovaginal candidiasis had cleared and then recurred. More likely, the repeat diagnoses at consecutive visits represent instances in which the vulvovaginal candidiasis was caused by Candida species not susceptible to fluconazole treatment. Previous research in India has found a high proportion of women infected by non-albicans Candida species $[29,33]$, which are more resistant to treatment with azoles [34, 35].

Of the sociodemographic and behavioral characteristics we examined, only age at initiation of sexual activity appeared to be associated with the prevalence of vulvovaginal candidiasis, such that those with later initiation of sexual activity had a higher prevalence of vulvovaginal candidiasis. As the number of years women had been with their sex partners was not associated with vulvovaginal candidiasis, these two sociodemographic results appear discrepant and warrant additional investigation.

We found a positive association between having clinically diagnosed bacterial vaginosis and vulvovaginal candidiasis. As both diagnoses include vaginal discharge as a component of their respective diagnostic criteria, it is very likely there 
TABle 3: Prevalence of vulvovaginal candidiasis by sociodemographic, behavioral, partner, and laboratory measures, Mysore, India 20052006.

Prevalent vulvovaginal candidiasis (Overall prevalence $=180 / 2528 ; 7.1 \%$ )

Prevalence $(n / N)$

Prevalence (\%)

Prevalence 95\% CI

Age, years

$16-20$
$21-25$
$26-30$

Years of education

0

$1-7$

8-17

Years with sex partner

$$
0-6
$$

7-19

Socioeconomic status***

Low

High

Parity

No

Yes

Religion*

Non-Muslim

Muslim

Age of initiation of sexual activity, years**

$<14$

15-18

$19+$

Number of vaginal sex acts in prior three months

$$
0-12
$$$$
\text { 13-120 }
$$

$14 / 157$

$72 / 978$

$94 / 1391$

$44 / 666$

$59 / 767$

$77 / 1095$

$55 / 728$

$124 / 1794$

$79 / 1257$

$101 / 1271$

$22 / 361$

$158 / 2164$

$116 / 1805$

$64 / 721$

$21 / 476$

$110 / 1460$

$49 / 590$

$65 / 769$

$115 / 1755$

Ever had anal sex

No

Yes

Husband has other sex partners

No

Yes

Tubal ligation

No

Yes

Herpes simplex virus type 2 infection

Negative

Positive

Trichomonas vaginalis infection

Negative

Positive

$167 / 2358$

$13 / 169$

$167 / 2371$

$13 / 157$

$65 / 910$

$115 / 1616$

$156 / 2201$

$24 / 327$

$169 / 2383$

$11 / 145$
9.2

7.4

6.6

6.6

7.7

7.0

7.5

6.9

6.3

7.9

6.0

7.3

6.4

8.9

4.4

7.5

8.2

8.2

$(6.0,10.5)$

6.6

$(5.4,7.8)$

7.1

$(5.9,8.2)$

7.6

$(3.6,11.5)$

7.1

(6.0, 8.2)

7.8

$(3.3,12.4)$

7.0

$(5.3,8.8)$

7.2

$(5.7,8.6)$

7.1

(5.9, 8.3)

6.9

$(4.0,9.8)$

7.1

$(5.8,8.3)$ 
TABle 3: Continued.

Prevalent vulvovaginal candidiasis (Overall prevalence $=180 / 2528 ; 7.1 \%$ )

\begin{tabular}{|c|c|c|c|}
\hline & Prevalence $(n / N)$ & Prevalence $(\%)$ & $\begin{array}{c}\text { Prevalence } \\
95 \% \text { CI }\end{array}$ \\
\hline \multicolumn{4}{|l|}{ Vaginal $\mathrm{pH}$} \\
\hline$<4.5$ & $54 / 868$ & 6.0 & $(4.3,7.7)$ \\
\hline$\geq 4.5$ & $126 / 1659$ & 7.7 & $(6.4,9.0)$ \\
\hline \multicolumn{4}{|c|}{$\begin{array}{l}\text { Clinical (Amsel) criteria diagnosis for } \\
\text { bacterial vaginosis** }\end{array}$} \\
\hline Negative & $145 / 2231$ & 6.5 & $(5.3,7.6)$ \\
\hline Positive & $35 / 296$ & 12.0 & $(8.2,15.8)$ \\
\hline \multicolumn{4}{|c|}{$\begin{array}{l}\text { Laboratory (Nugent) criteria diagnosis for } \\
\text { bacterial vaginosis }\end{array}$} \\
\hline Negative & $116 / 1633$ & 6.9 & $(5.6,8.3)$ \\
\hline Intermediate & $36 / 373$ & 9.8 & $(6.8,12.8)$ \\
\hline Positive & $21 / 391$ & 5.7 & $(3.1,8.2)$ \\
\hline \multicolumn{4}{|c|}{ Lactobacillus morphotypes detected* } \\
\hline$\geq 30$ & $123 / 1594$ & 7.5 & $(6.0,9.0)$ \\
\hline $5-29$ & $24 / 256$ & 9.6 & $(5.9,13.3)$ \\
\hline $1-4$ & $4 / 118$ & 3.7 & $(0.3,7.0)$ \\
\hline$<1$ & $5 / 134$ & 4.5 & $(0.8,8.2)$ \\
\hline 0 & $16 / 291$ & 5.5 & $(2.6,8.4)$ \\
\hline
\end{tabular}

Prevalences, 95\% confidence intervals and $P$ values calculated using generalized estimating equations with binary family, identity link, and exchangeable correlation.

$* 0.05 \leq P<0.10$.

$* * P<0.05$.

***A socioeconomic index was calculated using the first factor from a principle components analysis of household consumer goods, toilet type, financial instruments, and stove type, and then recoded into a binary score of low and high socioeconomic status [23].

is misclassification between vulvovaginal candidiasis and clinically defined bacterial vaginosis. For example, women infected with Candida may have discharge caused by bacterial vaginosis and could thus be misdiagnosed with vulvovaginal candidiasis [36]. Our findings emphasize the problems inherent in making diagnoses of vaginal conditions based on clinical examination alone $[34,37,38]$.

We found some evidence that the prevalence of vulvovaginal candidiasis varied with the presence of Lactobacillus morphotypes. The evidence for a relationship between the prevalence of vulvovaginal candidiasis and the presence of Lactobacillus in the vagina is conflicting, including studies in which the $\mathrm{H}_{2} \mathrm{O}_{2}$-production status of Lactobacillus was considered [24, 39-44]. Recently, a prospective cohort study of female sex workers in Kenya found the presence of Lactobacillus, regardless of $\mathrm{H}_{2} \mathrm{O}_{2}$-production status, was positively associated with prevalent vulvovaginal candidiasis (adjusted odds ratio (aOR) $2.3,95 \%$ CI $0.8,6.4$ ), a relationship that was strengthened after restricting the analysis to women without a diagnosis of bacterial vaginosis (aOR 3.8, 95\% CI 1.3, 10.8) [39].

The loss of vaginal Lactobacilli is the hypothesized mediator for the relationship between the receipt of antibiotics and the risk of vulvovaginal candidiasis $[1,5,45,46]$. The mediation hypothesis also underpins the long-standing interest in use of probiotic interventions to reduce the risk of developing vulvovaginal candidiasis $[1,47,48]$; the results here do not provide strong support for this hypothesis.

Strengths of this study include a large effective sample size derived from the use of participants' repeated observations, which allows for measurements of prevalence and incidence. Additionally, other studies of vulvovaginal candidiasis in India use samples of symptomatic women recruited from clinics or used syndromic diagnosis and as a result were not able to estimate the community-level prevalence of vulvovaginal candidiasis. Our study is one of the few to examine the prevalence of vulvovaginal candidiasis across a range in the number of Lactobacillus morphotypes detected in the vagina; examination of a dose-response provides better evidence, if any, of a biological relationship.

There are also important limitations of our study to consider. First, the women in this cohort were recruited by nonrandom sampling; unmeasured sampling bias can limit the generalizability of these results. Second, because of the cross-sectional nature of our analysis, we cannot make causal interpretations for the variations in the prevalence of vulvovaginal candidiasis observed here. Third, we were not able to speciate the Candida organisms detected. The associations between sociodemographic characteristics and potential risk factors and the prevalence of vulvovaginal candidiasis may differ by the Candida species which infect women, which are known to vary considerably by geographical location [1]. 
Fourth, we could not verify whether participants were selfmedicating between visits with antibiotics or antifungals, which would influence the incidence and prevalence measurements of vulvovaginal candidiasis. Further, we could not immediately followup with women treated for vulvovaginal candidiasis, and so could not verify whether treatment was successful. Finally, given the limited duration of the study, we could not identify a subset of women with recurrent vulvovaginal candidiasis, an important condition with epidemiologic features distinct from acute vulvovaginal candidiasis [49].

\section{Conclusions}

We found that syndromic diagnosis will result in substantial overdiagnosis and overtreatment of vulvovaginal candidiasis-negative women. For correct diagnosis of vulvovaginal candidiasis laboratory confirmation of vaginal infection with Candida is necessary as is a mean of assessing whether the discharge has been caused by bacterial vaginosis. Absent accurate means of diagnosing vulvovaginal candidiasis, women remain at risk for vulvovaginal candidiasisassociated negative birth outcomes and acquisition of sexually transmitted infections. Follow-up studies are needed of women infected with Candida yeast species to determine the risk factors for the yeast's overgrowth, as it appears that the examination of behavioral risk factors does not appear to be a fruitful avenue for further inquiry.

\section{Acknowledgments}

The authors thank Dr. Varalakshmi Chandrasekaran from the Public Health Research Institute of India, Chitra Karat from Holdsworth Memorial Hospital for assisting with the project, and Dr. Srikanth from St. John's Medical College and Jeanne Moncada from the University of California, San Francisco for providing technical support. The authors thank all the nongovernmental organizations who assisted with outreach programs and the women in the study for their participation. Funding was provided by the United States National Institute of Health Fogarty AIDS International Training and Research Program (Grant no. 1-D43TW00003-16). BioMed Diagnostics (White City, OR, USA) donated TV, GC, and yeast growth medium for the study. Focus Technologies (Cypress, CA, USA) donated HSV-2 Elisa kits. Cipla (Mumbai, India) donated oral Acyclovir.

\section{References}

[1] J. M. Achkar and B. C. Fries, "Candida infections of the genitourinary tract," Clinical Microbiology Reviews, vol. 23, no. 2, pp. 253-273, 2010.

[2] B. Foxman, R. Barlow, H. D'Arcy, B. Gillespie, and J. D. Sobel, "Candida vaginitis: self-reported incidence and associated costs," Sexually Transmitted Diseases, vol. 27, no. 4, pp. 230235, 2000.

[3] J. A. Røttingen, W. D. Cameron, and G. P. Garnett, "A systematic review of the epidemiologic interactions between classic sexually transmitted diseases and HIV: how much really is known?" Sexually Transmitted Diseases, vol. 28, no. 10, pp. 579-597, 2001.

[4] C. L. Roberts, J. M. Morris, K. R. Rickard et al., "Protocol for a randomised controlled trial of treatment of asymptomatic candidiasis for the prevention of preterm birth [ACTRN12610000607077]," BMC Pregnancy and Childbirth, vol. 11, article 19, 2011.

[5] J. D. Sobel, "Vulvovaginal candidosis," Lancet, vol. 369, no. 9577, pp. 1961-1971, 2007.

[6] A. M. Geiger, B. Foxman, and B. W. Gillespie, "The epidemiology of vulvovaginal candidiasis among university students," American Journal of Public Health, vol. 85, no. 8, pp. 11461148, 1995.

[7] H. L. Kent, "Epidemiology of vaginitis," American Journal of Obstetrics \& Gynecology, vol. 165, no. 4, pp. 1168-1176, 1991.

[8] J. Marrazzo, "Vulvovaginal candidiasis," British Medical Journal, vol. 326, no. 7397, pp. 993-994, 2003.

[9] J. H. Prasad, S. Abraham, K. M. Kurz et al., "Reproductive tract infections among young married women in Tamil Nadu, India," International Family Planning Perspectives, vol. 31, no. 2, pp. 73-82, 2005.

[10] R. A. Bang, M. Baitule, S. Sarmukaddam, A. T. Bang, Y. Choudhary, and O. Tale, "High prevalence of gynaecological diseases in rural Indian women," Lancet, vol. 1, no. 8629, pp. 85-88, 1989.

[11] S. Hawkes and K. G. Santhya, "Diverse realities: sexually transmitted infections and HIV in India," Sexually Transmitted Infections, vol. 78, no. 1, supplement, pp. i31-i39, 2002.

[12] R. Stephenson, M. A. Koenig, and S. Ahmed, "Domestic violence and symptoms of gynecologic morbidity among women in North India.," International Family Planning Perspectives, vol. 32, no. 4, pp. 201-208, 2006.

[13] M. Koenig, S. Jejeebhoy, S. Singh, and S. Sridhar, "Investigating gynaecological morbidity in India: not just another KAP survey," Reproductive Health Matters, vol. 6, no. 11, pp. 84-97, 1998.

[14] S. Garg, N. Sharma, P. Bhalla et al., "Reproductive morbidity in an Indian urban slum: need for health action," Sexually Transmitted Infections, vol. 78, no. 1, pp. 68-69, 2002.

[15] V. K. Desai, J. K. Kosambiya, H. G. Thakor, D. D. Umrigar, B. R. Khandwala, and K. K. Bhuyan, "Prevalence of sexually transmitted infections and performance of STI syndromes against aetiological diagnosis, in female sex workers of red light area in Surat, India," Sexually Transmitted Infections, vol. 79, no. 2, pp. 111-115, 2003.

[16] P. Madhivanan, K. Krupp, V. Chandrasekaran et al., "The epidemiology of herpes simplex virus type-2 infection among married women in Mysore, India," Sexually Transmitted Diseases, vol. 34, no. 11, pp. 935-937, 2007.

[17] P. Madhivanan, K. Krupp, V. Chandrasekaran et al., "Prevalence and correlates of bacterial vaginosis among young women of reproductive age in Mysore, India," Indian Journal of Medical Microbiology, vol. 26, no. 2, pp. 132-137, 2008.

[18] K. Krupp, P. Madhivanan, C. Karat et al., "Novel recruitment strategies to increase participation of women in reproductive health research in India," Global Public Health, vol. 2, no. 4, pp. 395-403, 2007.

[19] Centers for Disease Control and Prevention. Sexually transmitted diseases treatment guidelines. US Department of Health and Human Services, 2006.

[20] P. Madhivanan, K. Krupp, J. Hardin, C. Karat, J. D. Klausner, and A. L. Reingold, "Simple and inexpensive point-of-care tests improve diagnosis of vaginal infections in resource 
constrained settings," Tropical Medicine and International Health, vol. 14, no. 6, pp. 703-708, 2009.

[21] R. P. Nugent, M. A. Krohn, and S. L. Hillier, "Reliability of diagnosing bacterial vaginosis is improved by a standardized method of gram stain interpretation," Journal of Clinical Microbiology, vol. 29, no. 2, pp. 297-301, 1991.

[22] R. Amsel, P. A. Totten, and C. A. Spiegel, "Nonspecific vaginitis. Diagnostic criteria and microbial and epidemiologic associations," American Journal of Medicine, vol. 74, no. 1, pp. 14 22, 1983.

[23] S. Vyas and L. Kumaranayake, "Constructing socio-economic status indices: how to use principal components analysis," Health Policy and Planning, vol. 21, no. 6, pp. 459-468, 2006.

[24] S. E. Hawes, S. L. Hillier, J. Benedetti et al., "Hydrogen peroxide-producing lactobacilli and acquisition of vaginal infections," Journal of Infectious Diseases, vol. 174, no. 5, pp. 1058-1063, 1996.

[25] S. Vishwanath, V. Talwar, R. Prasad, K. Coyaji, C. J. Elias, and I. De Zoysa, "Syndromic management of vaginal discharge among women in a reproductive health clinic in India," Sexually Transmitted Infections, vol. 76, no. 4, pp. 303-306, 2000.

[26] S. Hawkes, L. Morison, S. Foster et al., "Reproductivetract infections in women in low-income, low-prevalence situations: assessment of syndromic management in Matlab, Bangladesh,” Lancet, vol. 354, no. 9192, pp. 1776-1781, 1999.

[27] S. Rahman, J. Bogaerts, R. Motiur, R. Razzak, K. Nessa, and M. Reza, "Validity assessment of flowcharts for syndromic management of vaginal discharge," Working Paper 158, ICDDR, B, Centre for Health and Population Research, Dhaka, Bangladesh, 2003.

[28] M. Romoren, M. Velauthapillai, M. Rahman, J. Sundby, E. Klouman, and P. Hjortdahl, "Trichomoniasis and bacterial vaginosis in pregnancy: inadequately managed with the syndromic approach," Bulletin of the World Health Organization, vol. 85, no. 4, pp. 297-304, 2007.

[29] S. Mohanty, I. Xess, F. Hasan, A. Kapil, S. Mittal, and J. E. Tolosa, "Prevalence \& susceptibility to fluconazole of Candida species causing vulvovaginitis," Indian Journal of Medical Research, vol. 126, no. 3, pp. 216-219, 2007.

[30] K. Puri, A. Madan, and K. Bajaj, "Incidence of various causes of vaginal discharge among sexually active females in age group 20-40 years," Indian Journal of Dermatology, Venereology and Leprology, vol. 69, no. 2, pp. 122-125, 2003.

[31] J. Thulkar, A. Kriplani, and N. Agarwal, "Utility of pH test \& Whiff test in syndromic approach of abnormal vaginal discharge," Indian Journal of Medical Research, vol. 131, no. 3, pp. 445-448, 2010.

[32] J. Bhatia and J. Cleland, "The contribution of reproductive illhealth to the overall burden of perceived illness among women in southern India," Bulletin of the World Health Organization, vol. 79, no. 11, pp. 1065-1069, 2001.

[33] A. Ahmad and A. U. Khan, "Prevalence of Candida species and potential risk factors for vulvovaginal candidiasis in Aligarh, India," European Journal of Obstetrics Gynecology and Reproductive Biology, vol. 144, no. 1, pp. 68-71, 2009.

[34] D. J. White and A. Vanthuyne, "Vulvovaginal candidiasis," Sexually Transmitted Infections, vol. 82, no. 4, supplement, pp. iv28-iv30, 2006.

[35] P. Nyirjesy, S. M. Seeney, M. H. T. Grody, C. A. Jordan, and H. R. Buckley, "Chronic fungal vaginitis: the value of cultures," American Journal of Obstetrics and Gynecology, vol. 173, no. 3, pp. 820-823, 1995.
[36] J. D. Sobel, S. Faro, R. W. Force et al., "Vulvovaginal candidiasis: epidemiologic, diagnostic, and therapeutic considerations," American Journal of Obstetrics and Gynecology, vol. 178, no. 2, pp. 203-211, 1998.

[37] V. Redondo-Lopez, C. Meriwether, C. Schmitt, M. Opitz, R. Cook, and J. D. Sobel, "Vulvovaginal candidiasis complicating recurrent bacterial vaginosis," Sexually Transmitted Diseases, vol. 17, no. 1, pp. 51-53, 1990.

[38] A. Schwiertz, D. Taras, K. Rusch, and V. Rusch, "Throwing the dice for the diagnosis of vaginal complaints?" Annals of Clinical Microbiology and Antimicrobials, vol. 5, no. 1, article 4, 2006.

[39] R. S. McClelland, B. A. Richardson, W. M. Hassan et al., "Prospective study of vaginal bacteria flora and other risk factors for vulvovaginal candidiasis," Journal of Infectious Diseases, vol. 199, no. 12, pp. 1883-1890, 2009.

[40] S. L. Hillier, M. A. Krohn, R. P. Nugent et al., "Characteristics of three vaginal flora patterns assessed by Gram stain among pregnant women," American Journal of Obstetrics and Gynecology, vol. 166, no. 3, pp. 938-944, 1992.

[41] V. D. Mijac, S. V. Dukic, N. Z. Opavski, M. K. Dukic, and L. T. Ranin, "Hydrogen peroxide producing lactobacilli in women with vaginal infections," Journal of Obstetrics \& Gynecology and Reproductive Biology, vol. 129, no. 1, pp. 69-76.

[42] P. Auger and J. Joly, "Microbial flora associated with Candida albicans vulvovaginitis," Obstetrics and Gynecology, vol. 55, no. 3, pp. 397-401, 1980.

[43] B. Zdolesk, D. Hellberg, G. Froman, S. Nilsson, and P. A. Mardh, "Vaginal microbiological flora and sexually transmitted diseases in women with recurrent or current vulvovaginal candidiasis," Infection, vol. 23, no. 2, pp. 81-84, 1995.

[44] R. C. R. Martinez, S. A. Franceschini, M. C. Patta et al., "Analysis of vaginal lactobacilli from healthy and infected Brazilian women," Applied and Environmental Microbiology, vol. 74, no. 14, pp. 4539-4542, 2008.

[45] J. Xu and J. D. Sobel, "Antibiotic-associated vulvovaginal candidiasis," Current Infectious Disease Reports, vol. 5, no. 6, pp. 481-487, 2003.

[46] L. O. Eckert, "Acute vulvovaginitis," The New England Journal of Medicine, vol. 355, no. 12, pp. 1244-1252, 2006.

[47] M. Pirotta, J. Gunn, P. Chondros et al., "Effect of lactobacillus in preventing post-antibiotic vulvovaginal candidiasis: a randomised controlled trial," British Medical Journal, vol. 329, no. 7465, pp. 548-551, 2004.

[48] T. E. Will, "Lactobacillus overgrowth for treatment of moniliary vulvovaginitis," Lancet, vol. 2, no. 8140, p. 482, 1979.

[49] P. A. Mårdh, A. G. Rodrigues, M. Genç, N. Novikova, J. Martinez-De-Oliveira, and S. Guaschino, "Facts and myths on recurrent vulvovaginal candidosis - A review on epidemiology, clinical manifestations, diagnosis, pathogenesis and therapy," International Journal of STD and AIDS, vol. 13, no. 8, pp. 522$539,2002$. 


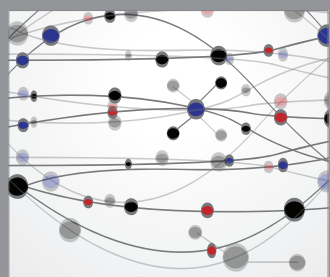

The Scientific World Journal
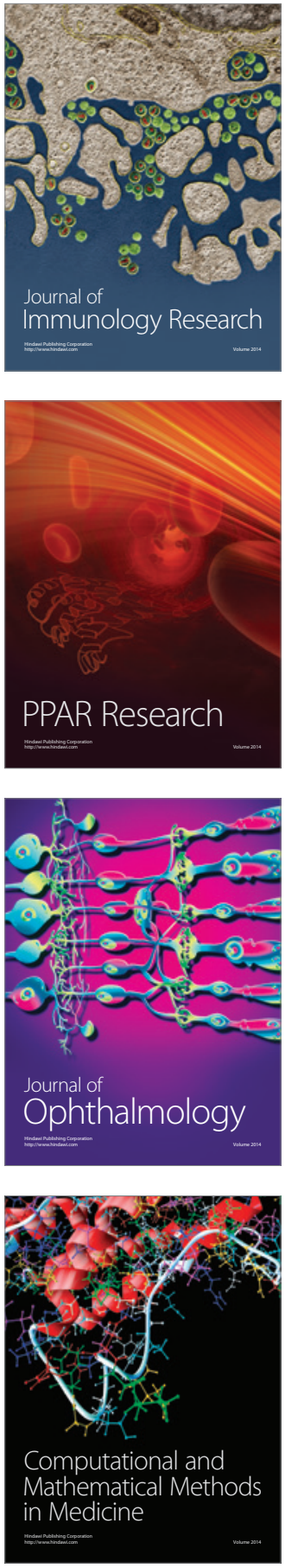

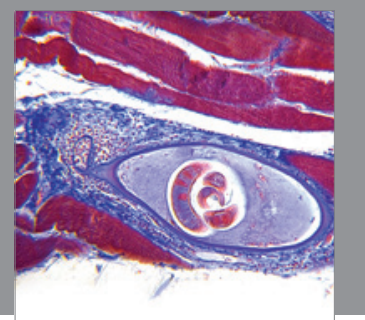

Gastroenterology

Research and Practice
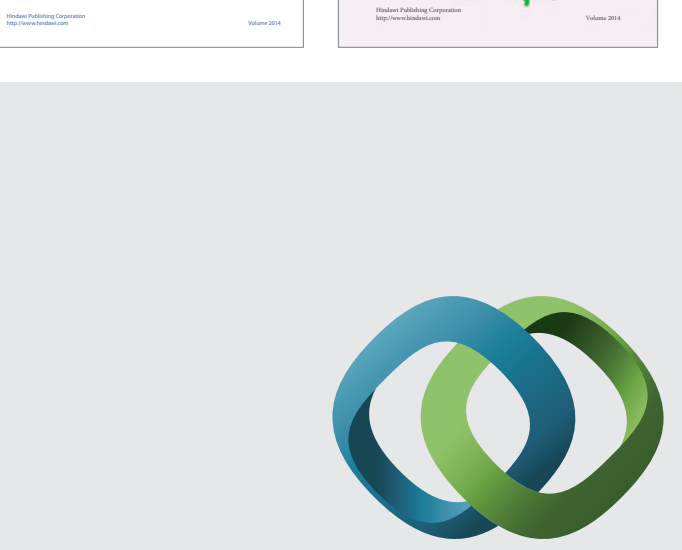

\section{Hindawi}

Submit your manuscripts at

http://www.hindawi.com
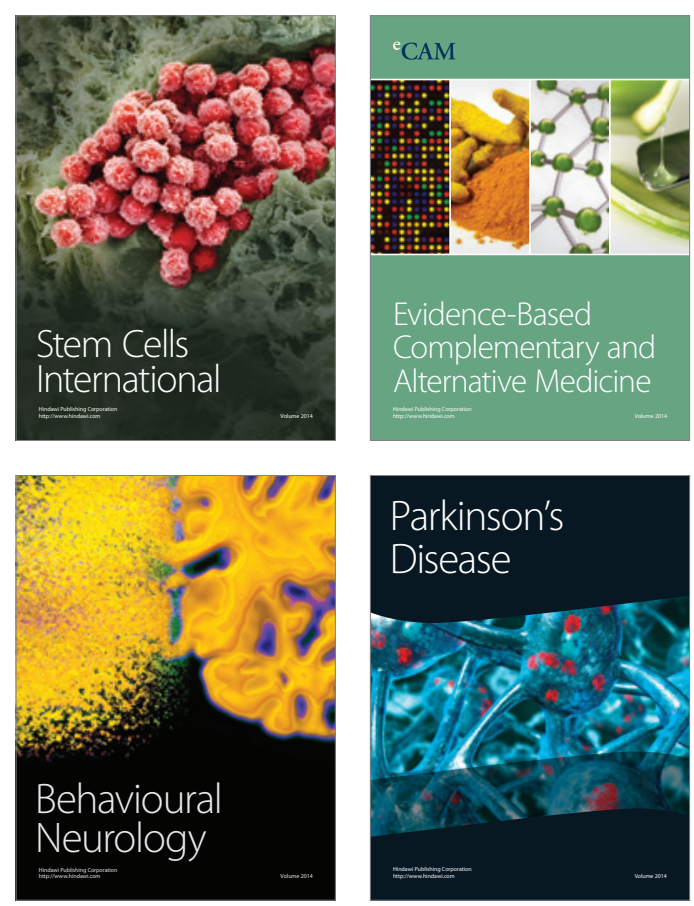

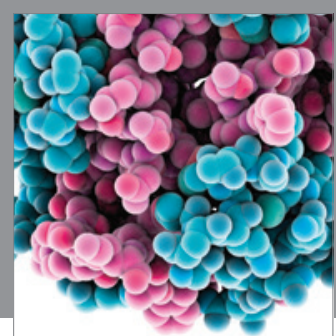

Journal of
Diabetes Research

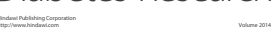

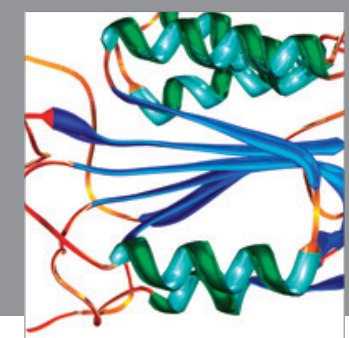

Disease Markers
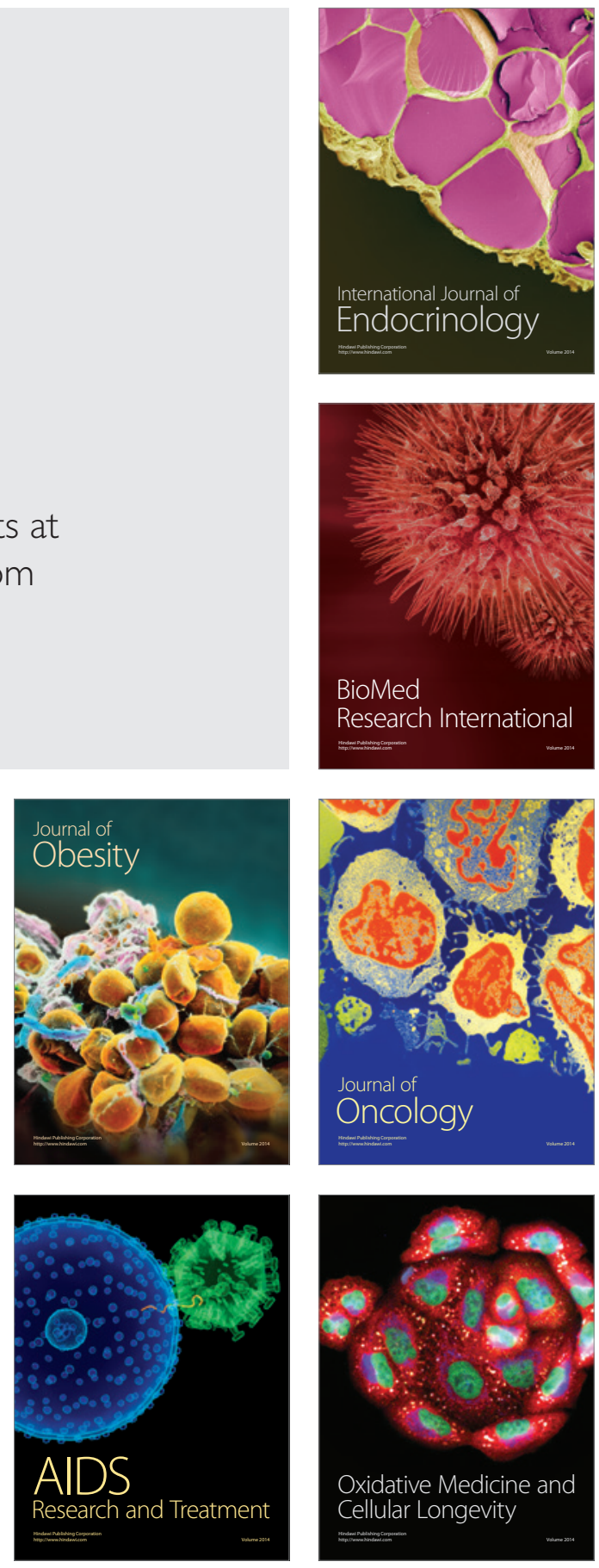